\title{
First report of corn cyst nematode, Heterodera zeae in Afghanistan
}

\author{
R. Asghari • E. Pourjam • R. Heydari • Z. Tanha Maafi • \\ A. M. Latifi
}

Received: 18 February 2013 /Accepted: 22 May 2013 /Published online: 22 June 2013

(C) Australasian Plant Pathology Society Inc. 2013

\begin{abstract}
The corn cyst nematode, Heterodera zeae was found in soil sample collected from five wheat fields with a history of corn cultivation in Nangharhar province, Afghanistan, during May-June 2009. Morphological and morphometric characters of cysts and second stage juveniles were in agreement with those described for this species in other countries. Comparison of the sequences of the large subunit (LSU) of rRNA gene with the data in Genbank supported our classical identification. The occurrence of $H$. zeae is reported for the first time in Afghanistan.
\end{abstract}

Keywords Afghanistan · Corn cyst nematode $\cdot$ Heterodera zeae $\cdot$ Identification $\cdot$ New record

Hetrodera zeae was first described from corn (Zea mays L.) by Koshy et al. (1971) from Rajasthan state, India. Subsequently, it was recorded from some other countries in Asia i.e. Pakistan (Maqbool 1981; Maqbool and Hashmi 1984; Shahina and Maqbool 1990), Thailand (Chinnasri et al. 1995), Africa; Egypt (Aboul-Eid and Ghorab 1983), the United States of America (Eisenback et al. 1993), Portugal

\footnotetext{
R. Asghari $\cdot$ E. Pourjam $(\bowtie)$

Department of Plant Pathology, College of Agriculture, Tarbiat

Modares University, Tehran, Iran

e-mail: pourjame@modares.ac.ir

R. Heydari

Department of Plant Protection, College of Agriculture and

Natural Resources, University of Tehran, Karaj, Iran

Z. Tanha Maafi

Department of Nematology, Iranian Institute of Plant Protection,

Tehran, Iran

A. M. Latifi

Applied Biotechnology Research Center, Baqiyatallah University of Medical Science, Tehran, Iran
}

(Correia and Abrantes 2005) and Greece (Skantar et al. 2012). Golden and Mulvey (1983) redescribed specimens from Maryland, USA and India. H. zeae is an economically important pest of corn in India (Koshy et al. 1971). Corn yield is adversely affected by the nematode even with good fertiliser practices (Krusberg et al. 1997).

During a survey of plant-parasitic nematodes in Nangharhar province in Afghanistan, cysts and second-stage juveniles (J2) of $H$. zeae were recovered from soil samples collected from five wheat fields with a history of corn cultivation. Morphological and morphometric characters and molecular identification are described here.

Twenty-two soil samples were collected from five wheat fields of Nangharhar province with a history of corn cultivation during May-June 2009. Each sample composed of six 200-250 g subsamples collected at depth 5-20 cm randomly. The nematodes were extracted from $300 \mathrm{~g}$ soil material by centrifugal flotation technique (Jenkins 1964), killed and fixed by FGA (formalin, glycerin and acetic acid) and transferred to glycerin according to the De Grisse method (1969). Cysts were extracted using a Fenwick can (Fenwick 1940). The excised vulval cone region was mounted in glycerin jelly. The specimens were studied under a Nikon E600 light microscope. The light microscopic photographs were taken using an automatic camera attached to microscope Olympus BX52. Classical identification was further verified by molecular study. Total genomic DNA was extracted as described by Tanha Maafi et al. (2003). The D2 and D3 expansion regions of the large subunit 28S rRNA gene were amplified by the forward D2A (5'-ACAAGTACCGTGAGGGAAAGTTG-3') and reverse D3B (5'-TCGGAAGGAACCAGCTACTA-3') primers (Subbotin et al. 2006). The regions were sequenced after purification of PCR products from the gel slice with a Qiagen gel purification kit (Qiagen Inc., Valencia, CA) and compared with available sequences of this region in databases. 


\section{Heterodera zeae Koshy et al. 1971}

Cysts (Fig. 1): measurements: $(n=8)$ length (excluding neck $)=$ $465 \pm 45.3(400-502) \mu \mathrm{m}$, width $=366 \pm 44(311-401) \mu \mathrm{m}$, length $/$ width $=1.2 \pm 0.04$ (1.2-1.3), fenestral length $=47.5 \pm$ $6.3(38-56) \mu \mathrm{m}$, semifenestral width $=32.8 \pm 6.4(22-42) \mu \mathrm{m}$, vulval slit length $=38.8 \pm 3.3(33-43) \mu \mathrm{m}$, underbridge length $=$ $37 \pm 6.1(28-45) \mu \mathrm{m}$.

Cysts were light brown in colour, thin walled and without a subcrystalline layer, lemon-shaped with terminal area protruding. The cyst wall pattern on the body proper was in the form of a zig-zag pattern. The vulval cone was prominent. The endon view of the vulval cone showed concentric lines of cuticular ridges around the vulval slit and fenestra. Fenestrae were ambifenestrate with the two semifenestrae separated by a vulval bridge and surrounded by a wide 'basin' (Fig. 1a and b). Four finger-like bullae were prominent and were immediately below the underbridge in a distinct formation (Fig. 1c and d). Below the finger like bullae a number of randomised bullae present. Underbridge simple, short, and thin. Vulva slit long, anus not conspicuous.

Second-stage juveniles (Fig. 2): measurements: $(n=8)$ length $=426.4 \pm 26.6(381-452) \mu \mathrm{m}$, body width at midbody $=$ $17.4 \pm 1(16-19) \mu \mathrm{m}$, lip region height $=4.2 \pm 0.5(3.5-5.0) \mu \mathrm{m}$, lip region width $=8.3 \pm 0.3(8.0-8.5) \mu \mathrm{m}$, stylet length $=22 \pm$ 1.1 (21-24) $\mu \mathrm{m}, a=24.6 \pm 1.6(21.8-27.0), b=5.1 \pm 0.8$ (4.0
6.5), $c=9.8 \pm 1.3(8.6-12.3), c^{\prime}=4.2 \pm 0.4(3.6-5.0)$, hyaline $=$ $24.4 \pm 2(22-27) \mu \mathrm{m}$, tail $=44 \pm 4.9(35-49) \mu \mathrm{m}$.

The second-stage juveniles were vermiform and cylindrical, tapering at both ends. Lateral field one-third of body width, with four incisures. Head continuous with body contour, with three annules. Cephalic frame-work moderately sclerotized. Stylet slender 21-24 $\mu \mathrm{m}$ long, conus half of stylet length or slightly shorter, stylet knobs large with anterior surface directed anteriorly. Orifice of dorsal oesophageal gland 3.5-5.0 $\mu \mathrm{m}$ behind stylet base. Excretory pore at $84-110 \mu \mathrm{m}$ from anterior end. Hemizonid 3-4 annules long situated 2-3 anuules anterior to the excretory pore. Phasmids small, conspicuous, 4-8 annules posterior to anus level (Fig. $2 \mathrm{~h}$ and i). Tail short, conically tapering with rounded terminus.

Females and males: Not found.

Heterodera zeae belongs to the Schachtii group. It is most closely related to $H$. glycines, $H$. schachtii and $H$. trifolii and differs from them by some morphologic and morphometric characters of cysts and J2. There are four finger-like bullae in the vulval cone immediately below a short, thin underbridge and many randomly located bullae below these in $H$. zeae versus no finger-like bullae and many large, randomised bullae below a strongly developed underbridge in the other three species. The $\mathrm{J} 2$ of $H$. zeae also differ from those of $H$. glycines, $H$. schachtii, $H$. trifolii by having a low, rounded head versus a high, less rounded head in the other three
Fig. 1 Photomicrographs of Heterodera zeae. Cyst (a-d). a, b: Vulval area showing ambifenestrate fenestration and vulval slit along vulval bridge, c: Vulval areas showing fingerlike bullae (arrows) and other bullae d: Lateral view of vulva cone, arrows showing fingerlike and normal bullae
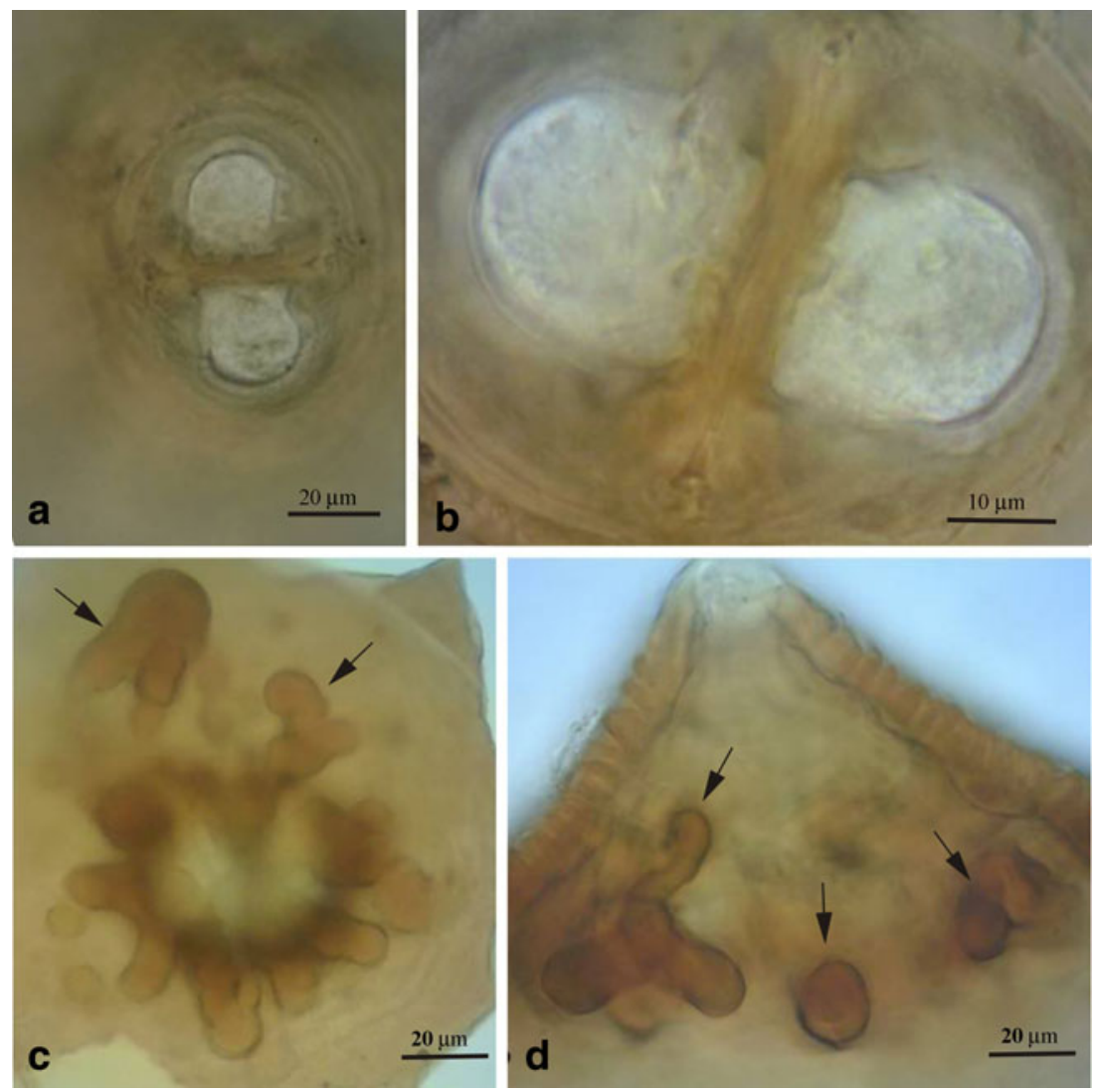
Fig. 2 Line drawings of Heterodera zeae. Second-stage juvenile (a-i). a: Entire body, b: Pharyngeal region, $\mathbf{c}, \mathbf{d}$ :

Anterior body region, e: Lateral field at midbody, $\mathbf{f}-\mathbf{i}$ : Tail
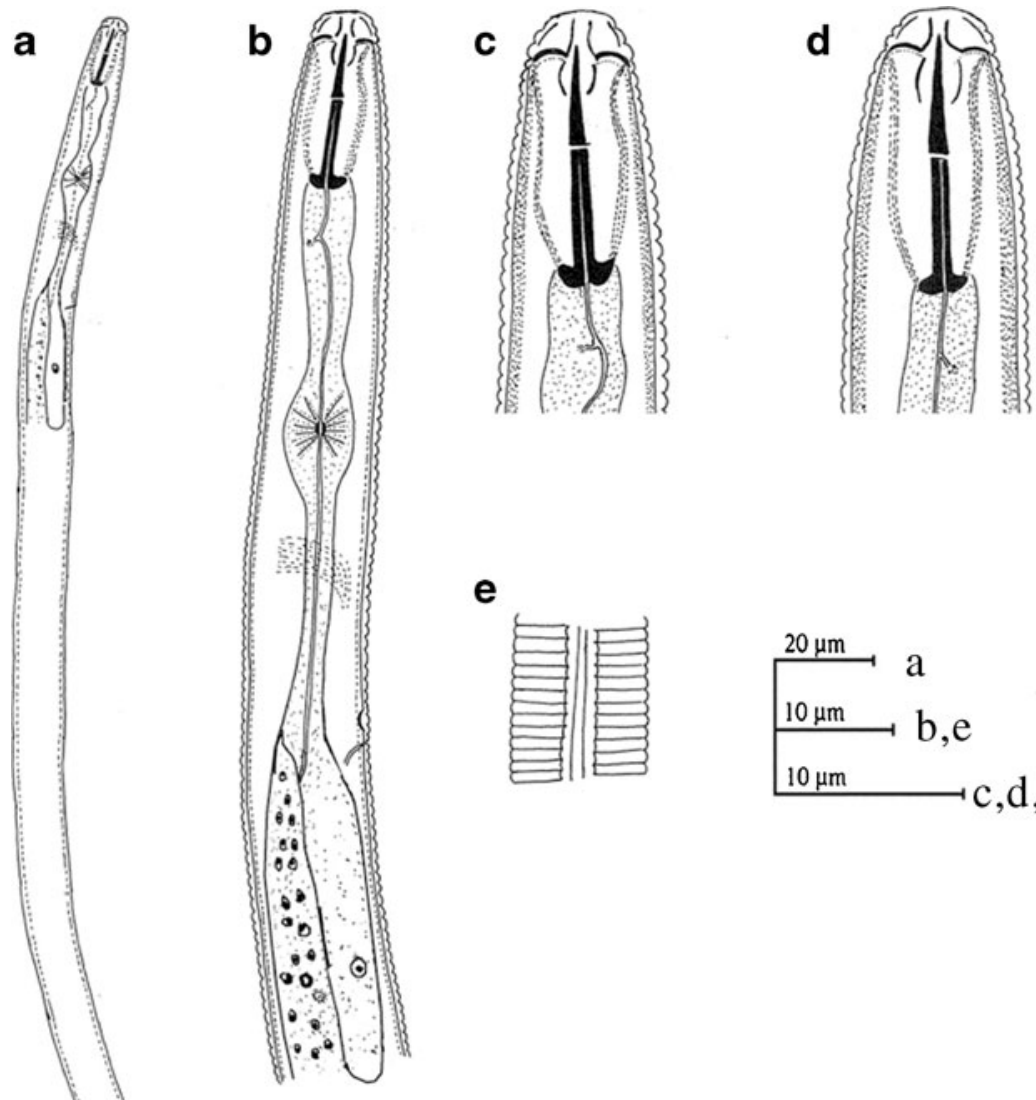

e
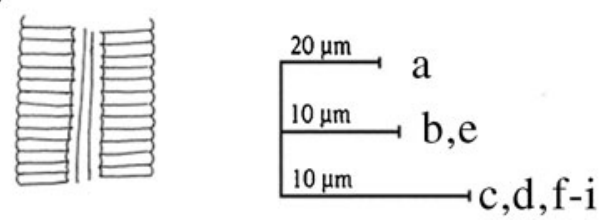
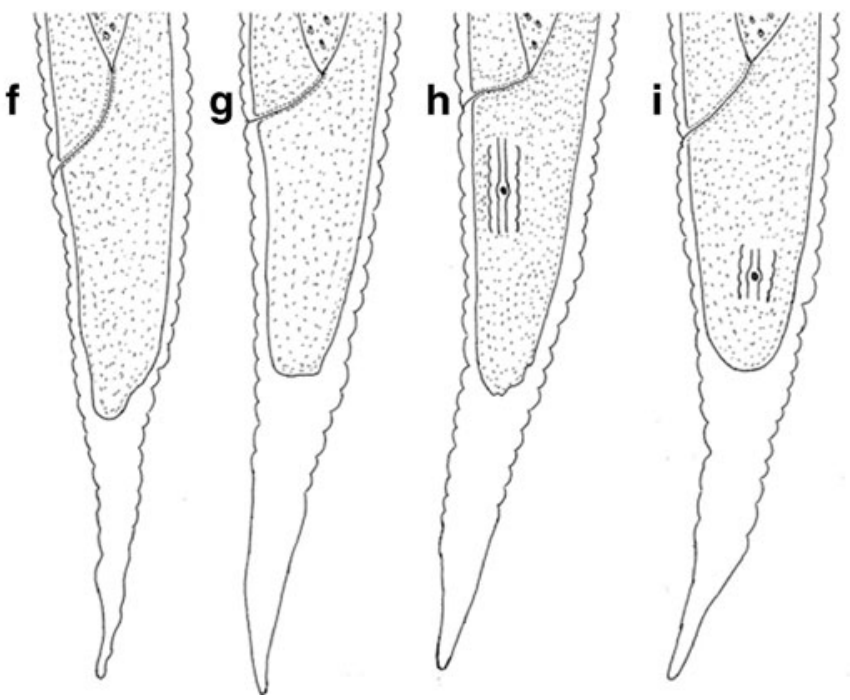

species; and a shorter stylet (average length $22 \mu \mathrm{m}$ ) versus a longer stylet (av. 23.0, 25.6 and $27.5 \mu \mathrm{m}$ ) for H. glycines, H.schatchii and H. trifolii, respectively. The tail of $H$. zeae second stage juvenile is shorter (average length $44 \mu \mathrm{m}$ ) than that of $H$. schatchii (av. $48.5 \mu \mathrm{m}$ ) and H. trifolii (av. $59.9 \mu \mathrm{m}$ ).

The measurements of the Afghanistan population of $H$. zeae are in close agreement with the original measurements of the nematode by Koshy et al. (1971), stylet length of the second stage juvenile differs from population reported from the United States (19.0-20.7 $\mu \mathrm{m}$ vs. 21-24 $\mu \mathrm{m})$ Golden and Mulvey (1983).

Seven microscopic slides of vulval cone sections and second stage juveniles (HZ 0012,1-HZ 0012,7) were deposited in the Nematode Collection of the Faculty of Agriculture, Tarbiat Modares University, Tehran, Iran.

Molecular identification The amplification of D2-D3 expansion segments of $28 \mathrm{~S}$ rRNA gene yielded single 
fragment of $c a$. $800 \mathrm{bp}$ that was deposited in GenBank under accession number JN583885. The obtained sequence was compared by BLAST in NCBI and showed strong similarity with $H$. zeae from the United States and Greece (Accession Nos. DQ328695 and GU145612 respectively).

To our knowledge this is the first report of corn cyst nematode (H. zeae) from Afghanistan.

Acknowledgments The authors thank Mr. Hosseini and Mr. Mortazavi for their assistance in sampling. We also greatly appreciate the thoughtful comments and suggestions of the two anonymous reviewers.

\section{References}

Aboul-Eid HZ, Ghorab AL (1983) The occurrence of Heterodera zeae in maize fields in Egypt. Egyptian J Phytopathol 13:51-61

Chinnasri B, Tangchitsomkid N, Toida Y (1995) Heterodera zeae on maize in Thailand. Jpn J Nematol 24:35-38

Correia FJS, Abrantes IMO (2005) Characterization of Heterodera zeae Populations from Portugal. J Nematol 37:323-335

De Grisse AT (1969) Redescription ou modifications de quelques techniques utilisées dans l'étude des nematodes phytoparasitaires. Mededelingen Rijksfaculteit der Landbouwwetenschappen Gent $34: 351-369$
Eisenback JD, Reaver DM, Stromberg EL (1993) First report of corn cyst nematode (Heterodera zeae) in Virginia. Plant Dis 77:647

Fenwick DW (1940) Methods for the recovery and counting of cysts of Heterodera schachtii from soil. J Helminthol 18:155-172

Golden AM, Mulvey RH (1983) Redescription of Heterodera zeae, the corn cyst nematode with SEM observations. J Nematol 15:60-70

Jenkins WR (1964) A rapid centrifugal-flotation technique for separating nematodes from soil. Plant Disease Rep 48:692

Koshy PK, Swarup G, Sethi CL (1971) Heterodera zeae n. sp. (Nematoda: Heteroderidae), a cyst-forming nematode on Zea mays. Nematologica 16:511-516

Krusberg LR, Sardanelli S, Grybauskas AP (1997) Damage potential of Heterodera zeae to Zea mays as affected by edaphic factors. Fundam Appl Nematol 20:593-599

Maqbool MA (1981) Occurrence of root-knot and cyst nematodes in Pakistan. J Nematol 13:448-449

Maqbool MA, Hashmi S (1984) New host records of cyst nematodes. Heterodera zeae and $H$. mothi from Pakistan. Pak J Nematol 2:99-100

Shahina F, Maqbool MA (1990) Distribution of corn cyst and cereal cyst nematodes in Pakistan. Int Nematol Netw Newslett 7:38-40

Skantar AM, Handoo ZA, Zanakis GN, Tzortzakakis EA (2012) Molecular and Morphological Characterization of the Corn Cyst Nematode, Heterodera zeae, from Greece. J Nematol 44:58-66

Subbotin SA, Sturhan D, Chizhov VN, Vovlas N, Baldwin JG (2006) Phylogenetic analysis of Tylenchida Thorne, 1949 as inferred from D2 and D3 expansion fragments of the 28S rRNA gene sequences. Nematology 8:455-474

Tanha Maafi Z, Subbotin SA, Moens M (2003) Molecular identification of cyst-forming nematodes (Heteroderidae) from Iran and a phylogeny based on ITS-rDNA sequences. Nematology 5:99-111 